\title{
Improving debris flow monitoring in Taiwan by using high-resolution rainfall products from QPESUMS
}

\author{
Chien-Yuan Chen · Lee-Yao Lin · Fan-Chieh Yu • \\ Ching-Sheng Lee $\cdot$ Chun-Chieh Tseng • \\ An-Hsiang Wang $\cdot$ Kei-Wai Cheung
}

Received: 15 March 2005/Accepted: 20 April 2006/

Published online: 17 November 2006

(C) Springer Science+Business Media B.V. 2006

\begin{abstract}
Debris flow is commonly initiated by torrential rain and its triggering is correlated to the hydrological, geological, and geomorphic conditions on site. In spite of the important effects of geology and topography, rainfall characteristic is the main external triggering factor to debris flow and is a predominant parameter for real-time monitoring. Due to the scarcity of sufficient spatial ground-based rainfall data in hill areas, quantitative precipitation estimation using remote-sensing techniques such as radar and satellite is needed for debris flow pre-warning. The QPESUMS (Quantitative Precipitation Estimation and Segregation Using Multiple Sensors) system was acquired to retrieve spatial rainfall data during the rainfall period from June 30 to July 6 in 2004 when Typhoon Mindulle and southwesterly flow struck Taiwan. The retrieved data were used for setting up the debris flow monitoring algorithm. With the aid of multiple platforms of meteorological observations, a rainfall threshold isohyet in a pilot area was mapped for debris flow monitoring. The rainfall monitoring algorithm based on QPESUMS provides more detailed information than the limited number of ground-based rainfall stations for interpreting the spatial distributions of rainfall events, and therefore is more suitable for debris-flow monitoring.
\end{abstract}

Keywords Debris flow $\cdot$ QPESUMS $\cdot$ Real-time monitoring

C.-Y. Chen $(\varangle) \cdot$ L.-Y. Lin $\cdot$ C.-C. Tseng $\cdot$ A.-H. Wang $\cdot$ K.-W. Cheung National Science \& Technology Center for Disaster Reduction,

9F., No. 200, Sec. 3, Beisin Rd., Sindian City, Taipei County 23143, Taiwan

e-mail: chienyuc@ncdr.nat.gov.tw

F.-C. $\mathrm{Yu}$

National Chung Hsing University, Taichung 402, Taiwan

C.-S. Lee

National Taiwan University, Taipei 106, Taiwan 


\section{Introduction}

Usually, real-time debris flow monitoring is performed using observed rain-gauge data according to pre-defined rainfall thresholds derived from historical debris flow cases (Chen et al. 2005). However, the watershed area of a debris flow river could be as small as a few kilometers across. Although there are 406 rainfall stations in Taiwan, each ground-based station has to represent the rainfall distribution in an area across ten kilometers or more and rainfall distribution within both the windward and leeward-facing slopes of the debris flow terrain is considered uniform. Obviously in this situation, the spatial rainfall distributions affected by topography are insufficiently represented within the 1420 catchments in Taiwan, especially in the slopeland and the upper stream of mountain areas.

Numerous rainfall parameters and their relationships reflecting the rainfall characteristics that initiated debris flow have been analyzed for setting up a prewarning baseline. These relationships include effective cumulative rainfall versus effective rainfall intensity (Caine 1980; Cannon and Ellen 1985; Wieczorek 1987), and rainfall duration versus rainfall intensity (Keefer et al. 1987; Crosta and Frattini 2002; Chen et al. 2005). Besides, parameters used for rainfall index consist of antecedent rainfall, daily rainfall and averaged rainfall intensity.

Wilson and Jayko (1997) used a critical rainfall isopleth map prepared by normalizing the rainfall intensity data by the mean annual precipitation of each raingauge, and the normalized rain intensity was used to represent the spatial rainfall variation in triggering debris flow. The weaknesses of debris-flow monitoring by ground-based rainfall stations is that the spatial variation of rainfall is not well monitored by the limited number of rain-gauge stations. Moreover, there are large interpolation errors in statistical analysis of the rain-gauge data.

The products developed by the US National Oceanic and Atmospheric Agency (NOAA, http://www.nssl.noaa.gov/western/qpe/) for rainfall estimation and weather forecasting have been used to forecast heavy rainfall that induced natural hazards such as flooding (Johnson et al. 1999, Yates et al. 2000; Young et al. 2000; Vieux et al. 2003). In the present analysis, data from the QPESUMS radar system is calibrated by rain-gauge stations for improving the spatial interpolation of rainfall distribution for debris-flow monitoring. Emphasis is put on the feasibility study of debris flow threshold monitoring by QPESUMS algorithm.

\section{Overview of QPESUMS in Taiwan}

The National Weather Bureau in Taiwan cooperated with the National Severe Storms Laboratory, NSSL of NOAA) and established four weather Doppler radar stations in Taiwan at the end of 2001 for improving the quality of quantitative precipitation estimations. Figure 1 depicts the position of the four weather Doppler radar stations in Taiwan. The scan radius of each radar is about $230 \mathrm{~km}$ and covers the island and the adjacent ocean. The Taiwan area is split into $441 \times 561$ grids with each cell representing an area of $1.25 \times 1.25 \mathrm{~km}$. Limited by the visibility of the radar scan range due to tilting of the radar dish, less precision in the higher altitude mountainous areas in Taiwan is expected.

Information from a network of 406 automatic rain gauges and 45 ground stations is used for real-time bias adjustment and is currently updated every $10 \mathrm{~min}$ for radar 
Fig. 1 Radar network in Taiwan

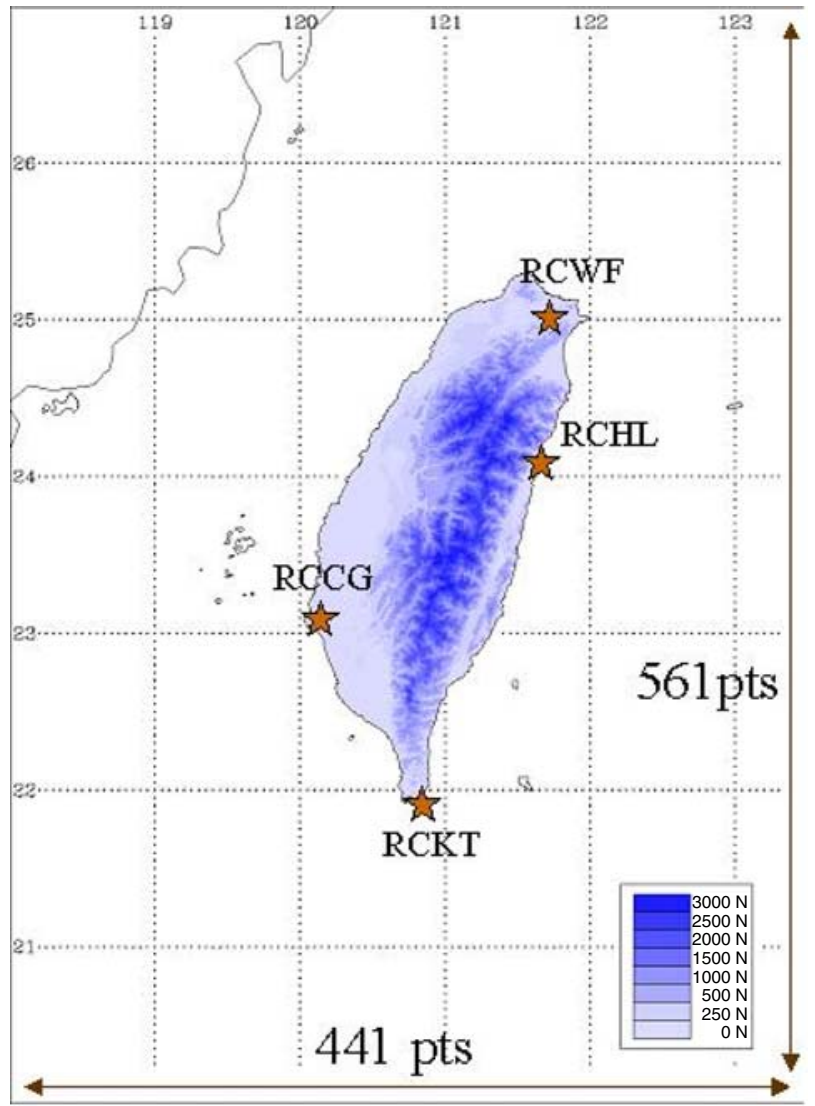

precipitation estimation. The QPESUMS system has been used to monitor typhoon rainfall (Lee et al. 2006) and for flood forecasting (Vieux et al. 2003) in Taiwan.

\section{Algorithm of QPESUMS for debris flow monitoring}

The radar precipitation estimation processes for debris flow threshold monitoring are categorized into five stages. Stage I is to retrieve hourly digital precipitation from QPESUMS's reflectivity-precipitation (power-law Z-R) relationship. Stage II process is a real-time bias correction process by the ground-based stations and mosaic multiple weather radars covering island wide. In stage III, precipitation data are presented in a Web Geographic Information System (GIS) similar to Xie et al.'s (2005) algorithm. Stage IV is to overlay the calibrated QPESUMS precipitation distribution and topographic map to retrieve representative grid points for quantitative precipitation estimation within a watershed. A representative grid point within the watershed is chosen as the overflow point of debris flow herein. The final stage $\mathrm{V}$ is to set up a critical isopleth map by interpolation of grid points within the watershed for debris flow threshold monitoring. Figure 2 presents the implemented algorithm for debris flow threshold monitoring by QPESUMS data. 


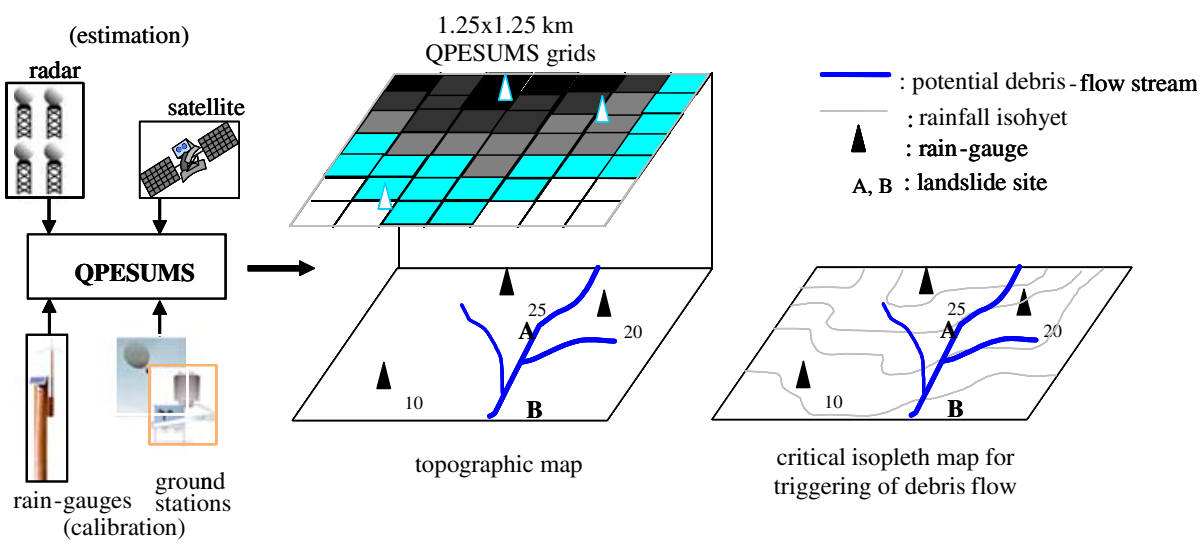

Fig. 2 Algorithm for applying QPESUMS data on debris flow monitoring

\section{Implementation and model sensitivity}

A case study at Nantou County in central Taiwan, which was struck by typhoon Mindulle in 2004, was chosen to implement the QPESUMS debris flow thresholdmonitoring algorithm. The present study is to investigate the feasibility of the algorithm on debris flow threshold monitoring.

\subsection{Site location}

Figure 3 presents the location of the case under study for QPESUMS monitoring. Puli town in Nantou County is located in central Taiwan. Puwu expressway (or called No. 14 expressway) from Puli town to Wushe town plays an important role in the Central Ridge Mountain areas and is a route to areas of eastern Taiwan. The monitoring area is about $13 \times 11 \mathrm{~km}$, along the expressway from the distance label of $60 \mathrm{~K}$ to $79 \mathrm{~K}$.

A total of 17 streams with a tendency for debris flow were monitored, with 4 streams located on the left side and 13 streams on the right side along the expressway crossing from west to east as shown in Fig. 4. The maximum catchment area is $1,823 \mathrm{ha}$ and the minimum is $10 \mathrm{ha}$. Several field investigations were performed after the typhoon impact for the debris flow hazards, overflow points and areas affected by delineating of debris masses. The four nearest rain-gauge stations are also presented in Fig. 4.

\subsection{Geologic and geomorphic conditions}

The main geology in the field is argillite interbedded with sandy shale and sandstone or argillite interbedded with slate and phyllite. In the subcatchments, the geologic condition shows fracture and numerous landslides were initiated during the Chi-Chi earthquake in 1999. The uppermost landslide area during the Chi-Chi earthquake in 1996 was 136 ha in Nantou A001 catchment. The study area is confined within two parallel faults, which contributed to the fractured geological conditions in the field. 


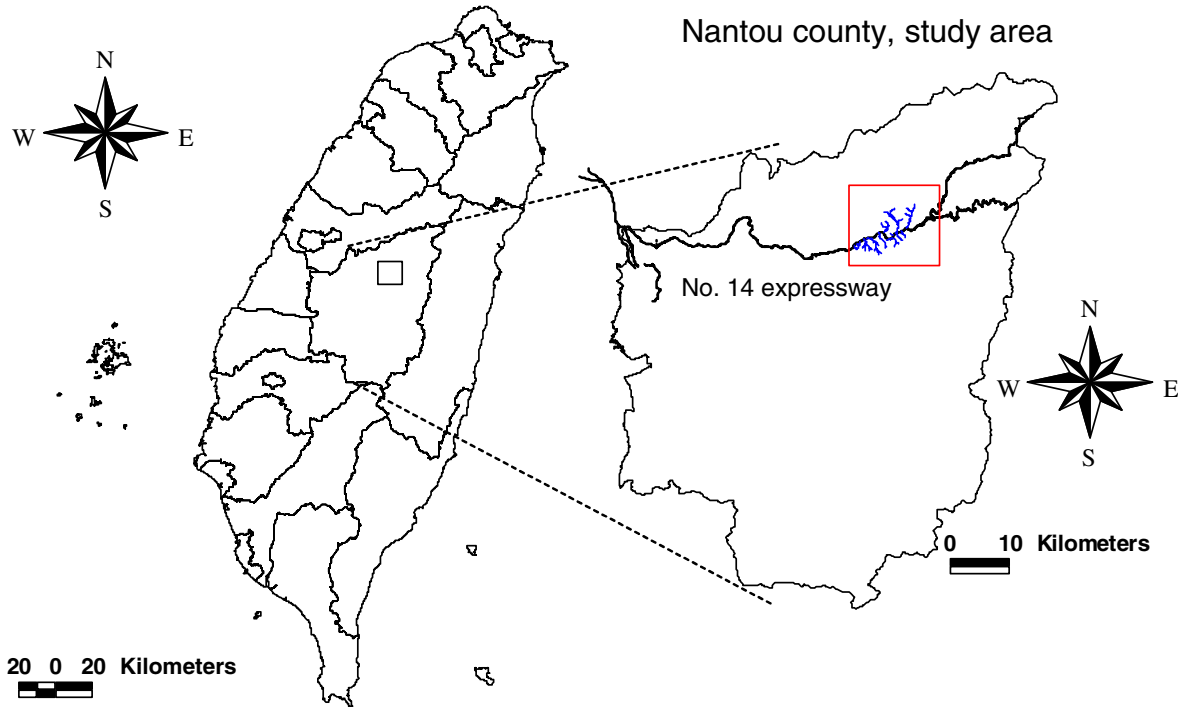

Fig. 3 Site location of study area

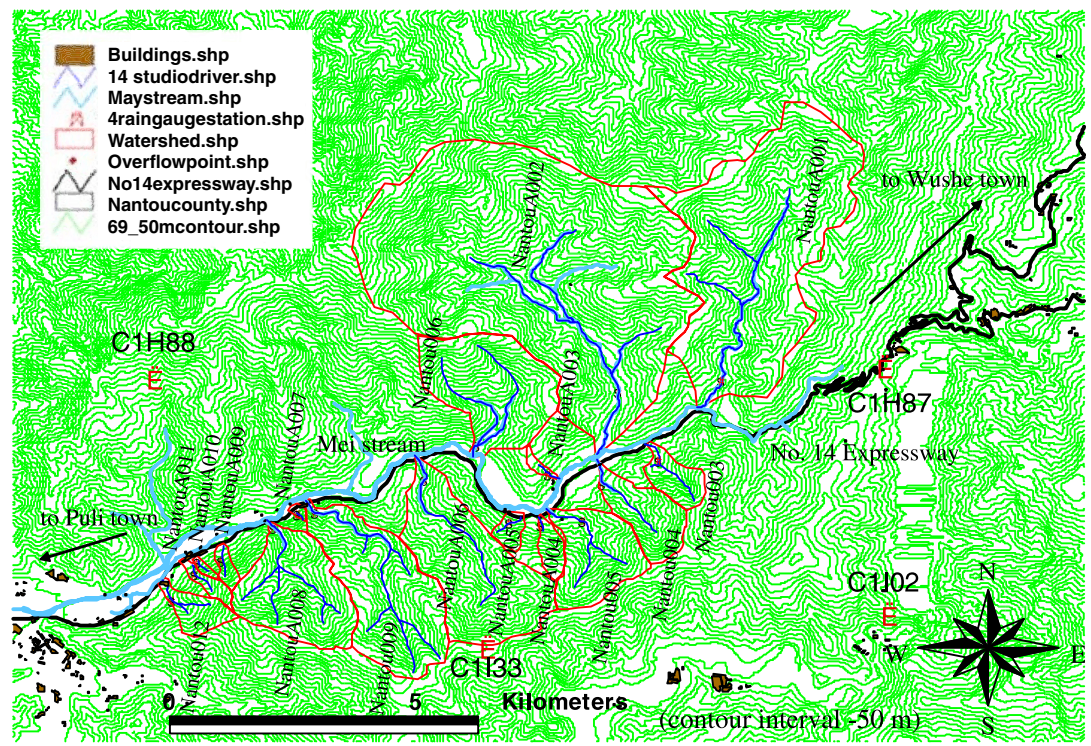

Fig. 4 Locations of the 17 debris flows and nearest rain-gauge stations in pilot area

Triggering sources of debris flow are commonly found in areas with gradients above $15^{\circ}$ (Takahashi 1981). The effects of steep slope and sufficient watershed area to accommodate adequate water are two conditions considered to initiate debris flow. The effective area $\left(A_{15}\right)$ is defined as that with slope above $15^{\circ}$ within the watershed. The greatest effective area is 631 ha in Nantou A002 among the studied watersheds. The falling head is defined as the elevation of the highest point in 


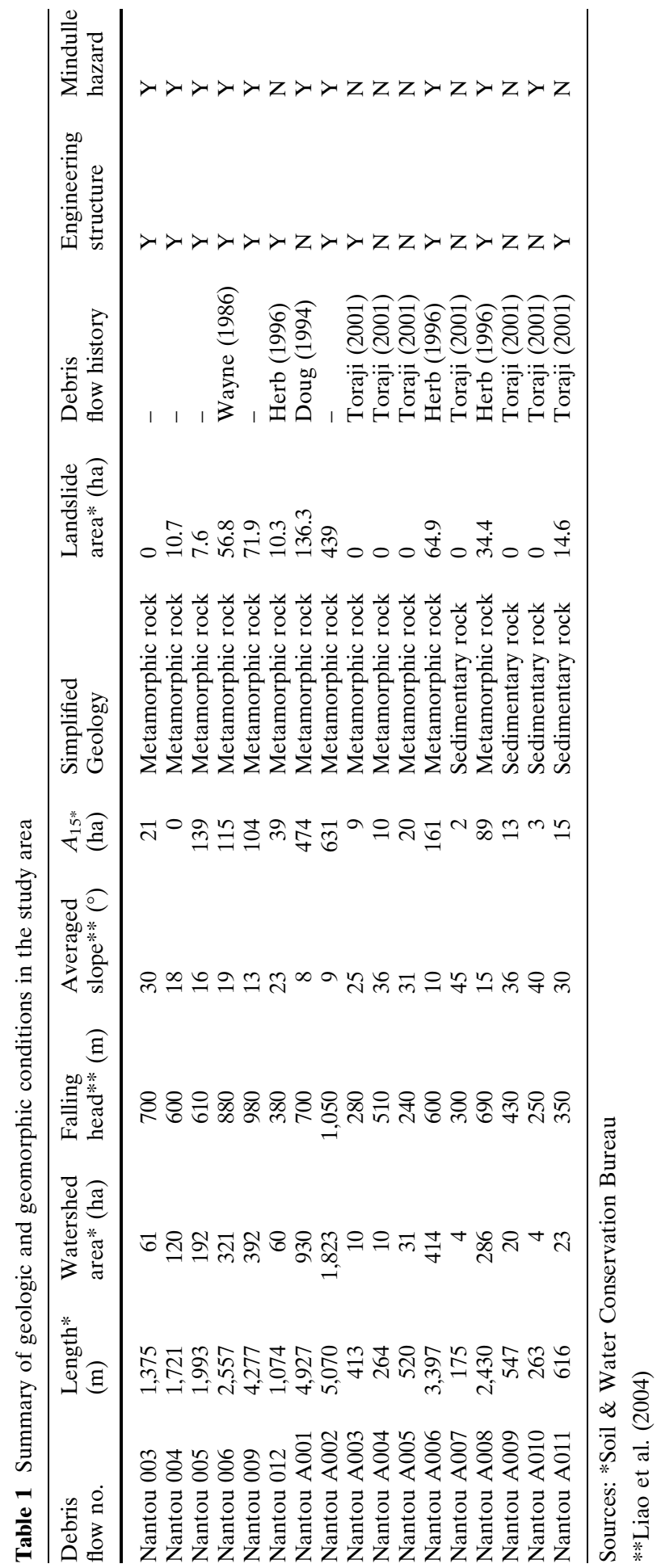


landslide scarp minus the lowest point of the stream at the outlet. It is expected that the higher the falling head, the farer debris masses will be mobilized. The topographic and land-surface characteristics extracted from digital terrain model (DTM) in GIS are summarized in Table 1 to identify each catchment.

\subsection{Debris flow hazards and initiation history}

There are 12 rivers that had debris flow initiation history among the 17 studied potential debris flow, in which 7 were initiated in 2001 during the Typhoon Toraji, 3 were initiated in 1996 that was caused by Typhoon Herb, one was triggered during Typhoon Doug in 1994, and one outburst in 1986 after Typhoon Wayne. In total 10, debris flow were triggered among these streams after Typhoon Mindulle struck Taiwan, among which half of these have debris flow initiation history. The time of debris flow initiated was between 20:00 and 21:00 on 4th July as recalled by a local resident.

Figure 5 illustrates a filling station impacted by the torrential debris at Nantou 004 debris flow site. At the outlet of debris flow Nantou 003, there were more than 10 buildings buried under the debris masses as shown in Fig. 6.

Among the ten debris flow cases induced after Typhoon Mindulle, there were eight sites with engineering facilities for debris flow prevention as referenced in Table 1. Field investigations after debris flow hazards revealed that the sources of debris masses from upstream were underestimated by engineering designs and resulted in debris masses overflowing in field. This also helps to explain the recurrent debris flow in the area. The sources of debris masses could originate from the landslides induced by the Chi-Chi earthquake in 1999 for these eight cases with historical landslides within the watershed and fractured geological conditions. Nine of the cases had a falling head of over $600 \mathrm{~m}$ and eight of them had an effective area $\left(A_{15}\right)$ more than 20 ha, which reveals that the terrain conditions had high tendency to initiate debris flow.

\subsection{Spatial rainfall distribution and model sensitivity}

The validation of radar estimated temporal rainfall history by ground based station data at the four rain gauge stations are presented in Fig. 7. In general, the rainfall time series by radar estimation agree well with those from ground-based stations up

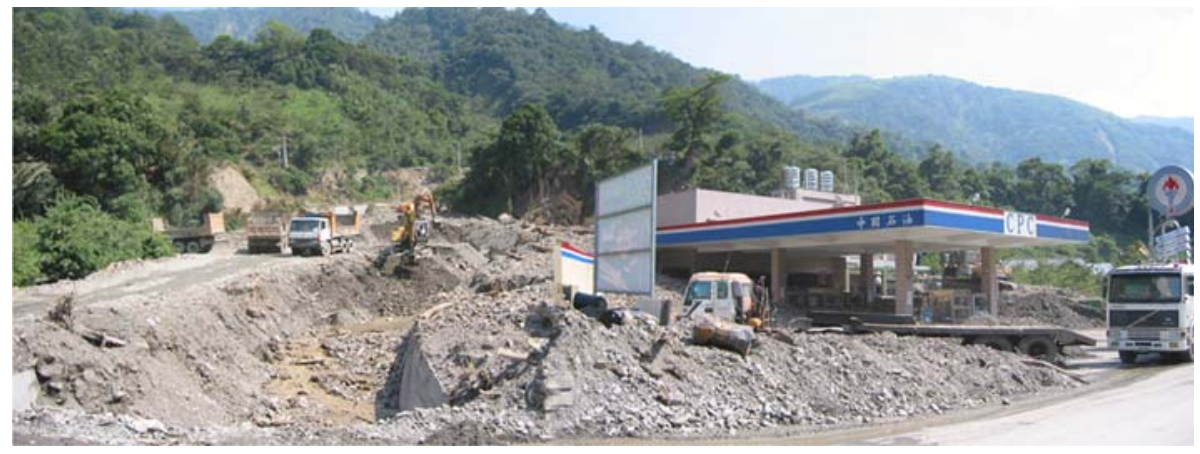

Fig. 5 Nantou 004 debris flow hazard 
Fig. 6 Aerial photo of Nantou 003 debris flow hazard (photo by Qi B. L.)

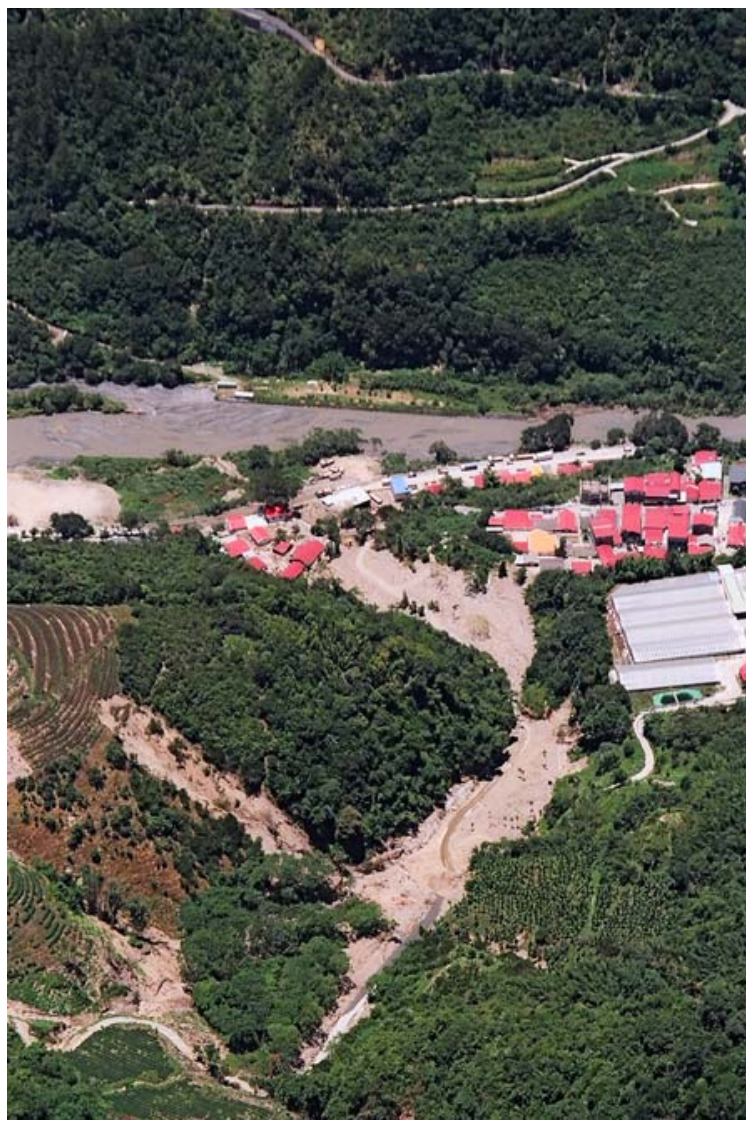

to the time of 23:00 on 4th July when the stations were broken down at that time. The radar data better estimated rainfall at rain-gauge stations C1I02 and C1I33 than at the stations $\mathrm{C} 1 \mathrm{H} 88$ and $\mathrm{C} 1 \mathrm{H} 87$, which could reflect the effects of the topography. Figure 8 shows the calibration equation used for the four nearest rain-gauge stations. The lowest degree of correlation in the calibration result of radar data versus rain-gauge stations is about $90 \%$.

Time series of rainfall history at the overflow points were retrieved from QPESUMS grid points and parts of the results are presented in Fig. 9. Typhoon-induced intense rainfall concentrated from 21:00, 1st July to 23:00, 4th July. The maximum rainfall intensity was $140 \mathrm{~mm} / \mathrm{h}$ and accompanied by a total accumulated rainfall up to $1,100 \mathrm{~mm}$ as retrieved at the grid point near rain-gauge station $\mathrm{C} 1 \mathrm{I} 33$ by radar.

The distribution of total accumulated rainfall in the area for both radar-retrieved and rain-gauge records were quite uniform during the period 1st to 5th July 2004 as presented in Fig. 10. In spite of the small diversity of the isohyet map prepared by radar-retrieved data from that using ground-based stations, the precipitation distribution based on the radar data is believed to be reliable and the fact that it possesses more datum points is a benefit for applying the Kriging interpolation analysis in the GIS. The maximum rainfall intensity for the rainfall event is shown in Fig. 11 for both radar estimation and ground-based rain stations. The regions of maximum 


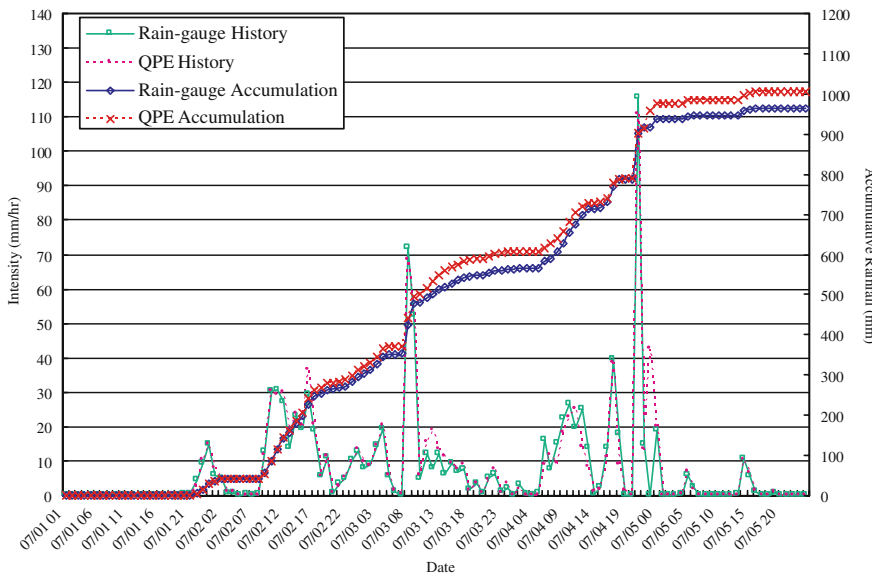

C1H88
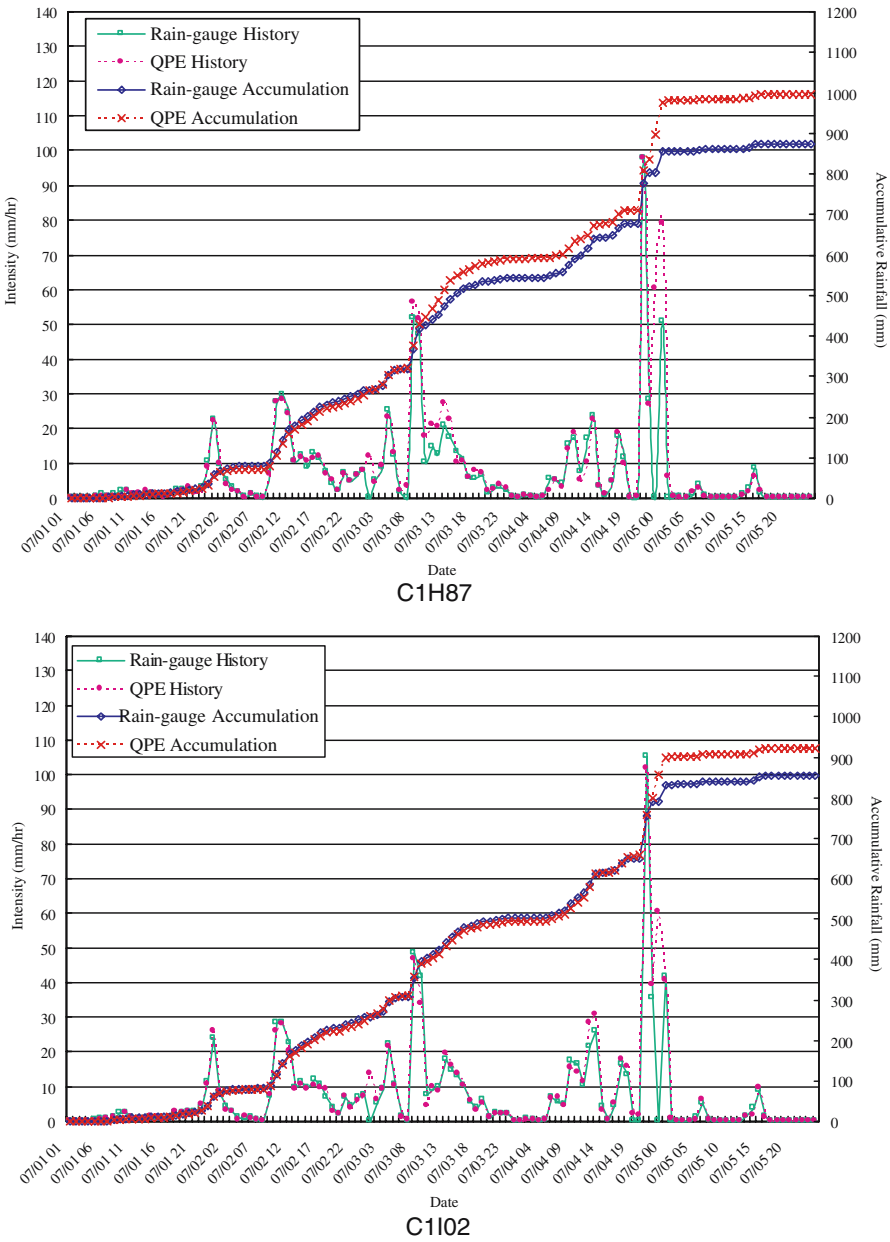

Fig. 7 Comparisons of rainfall time series by QPESUM acquired and rain gauge-based 


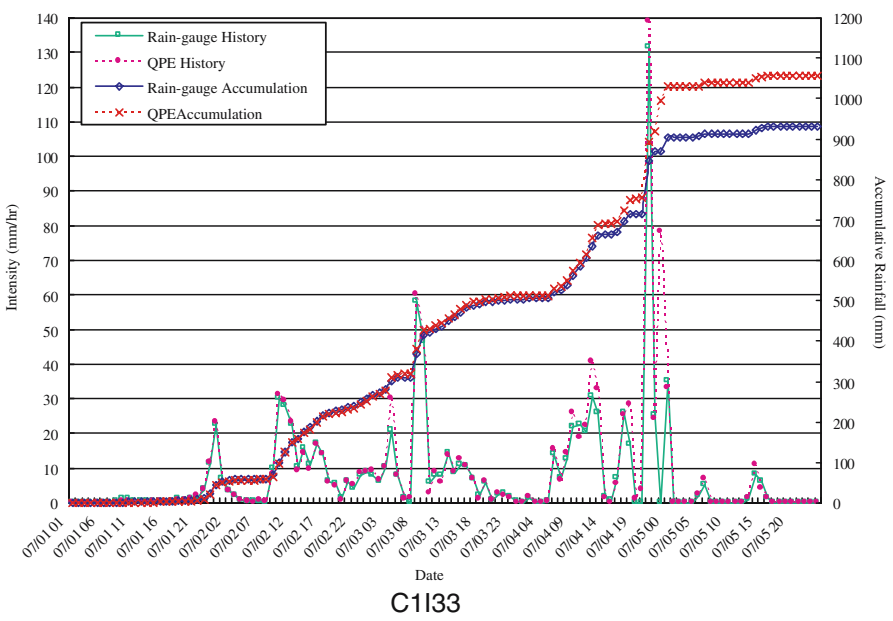

Fig. 7 continued

rainfall intensity crossed from northwest of leeward-facing slopes to southeast of windward-facing slopes, which reflects the characteristics of topology and the southwest cyclone. The maximum rainfall intensity on the west side of the study area was also higher than the east side.
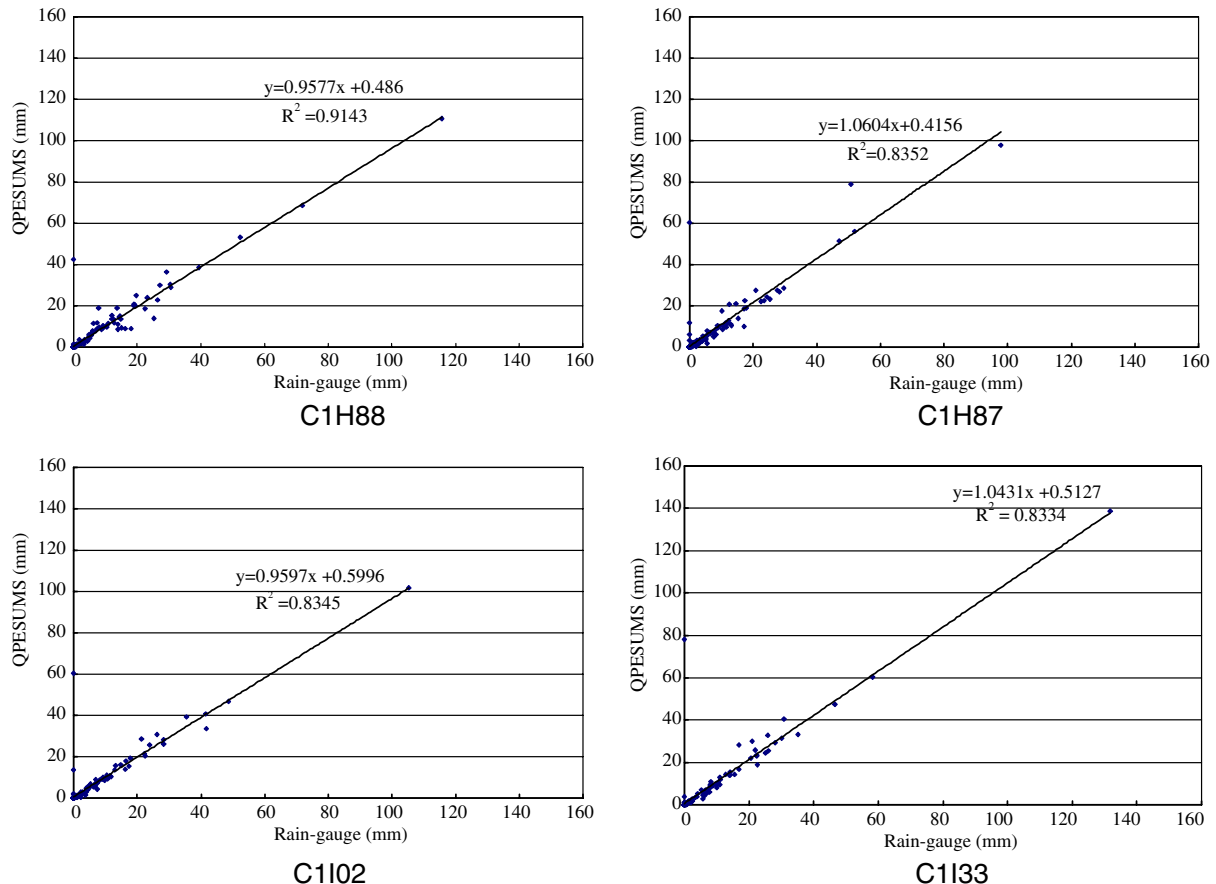

Fig. 8 Calibrated equations of QPESUMS and ground-based stations

를 Springer 


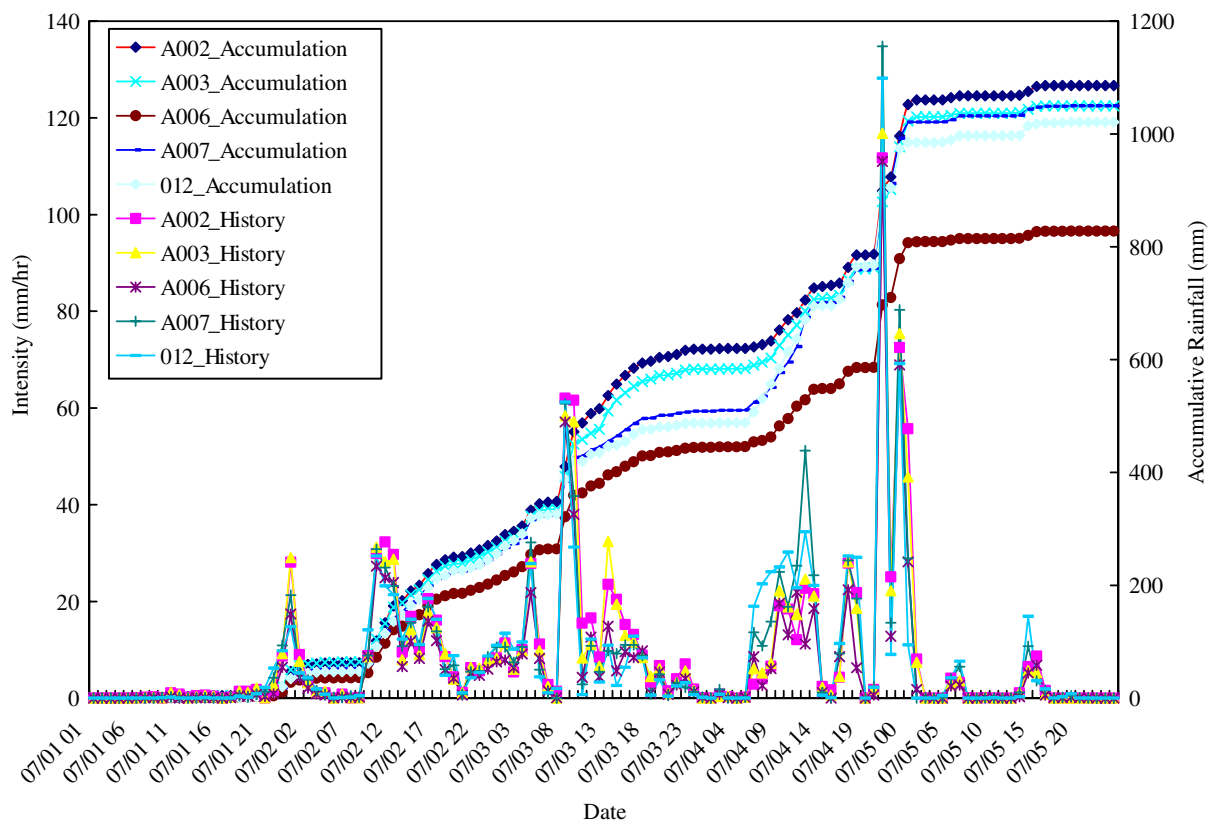

Fig. 9 Rainfall time history retrieved by QPESUMS at debris flow overflow points

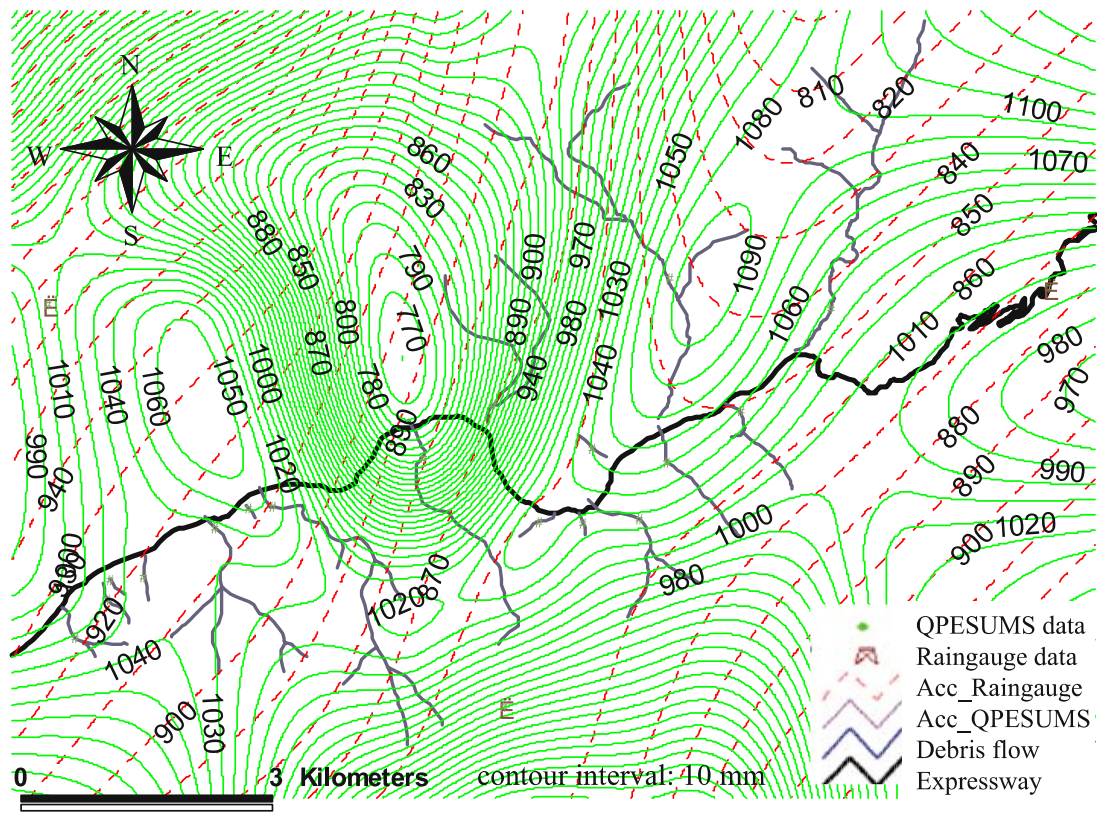

Fig. 10 Total accumulative rainfall from 1st to 5th July 2004 in the study area 


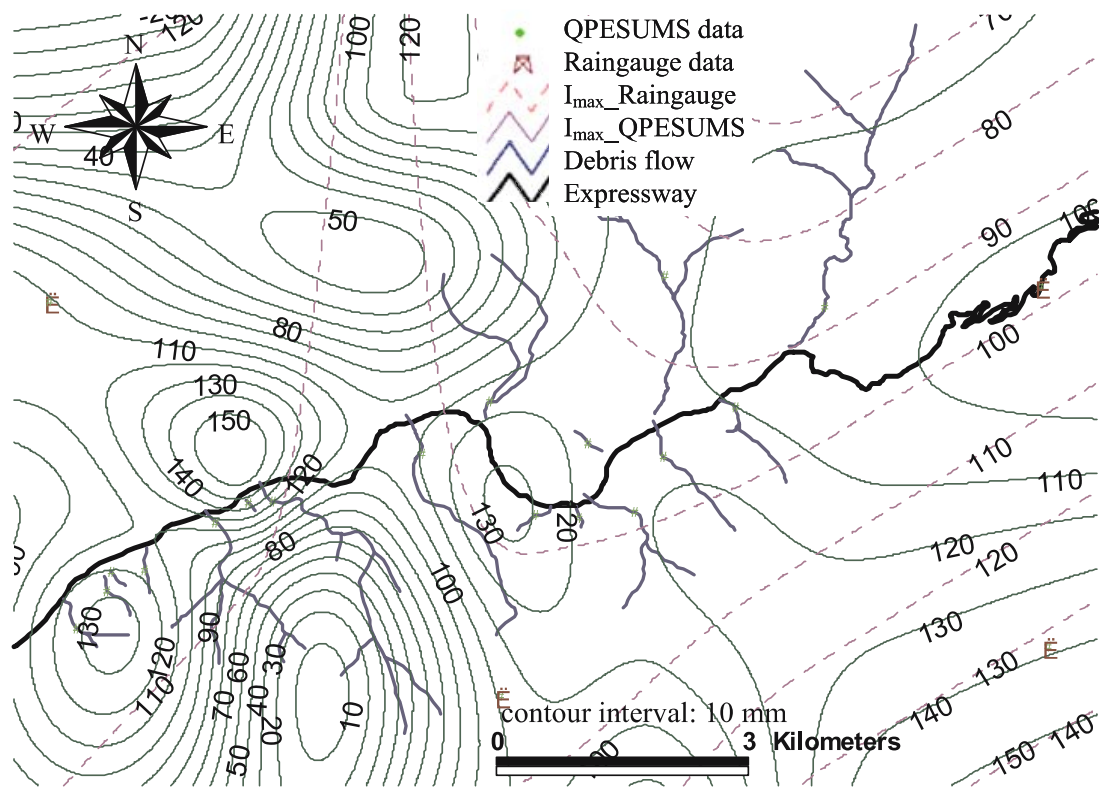

Fig. 11 Distributions of maximum rainfall intensity in the study area

\subsection{Rainfall threshold for debris flow monitoring}

A critical combination of rainfall intensity and duration is required to trigger debris flow in the San Francisco Bay region as found in Cannon and Ellen (1985), Wilson and Jayko (1997). In the earthquake-induced landslide areas, torrential rainfall-

Fig. 12 Averaged rainfall intensity $\left(I_{\text {avg }}\right)$ versus rainfall duration $(D)$ to trigger debris flow in the study area

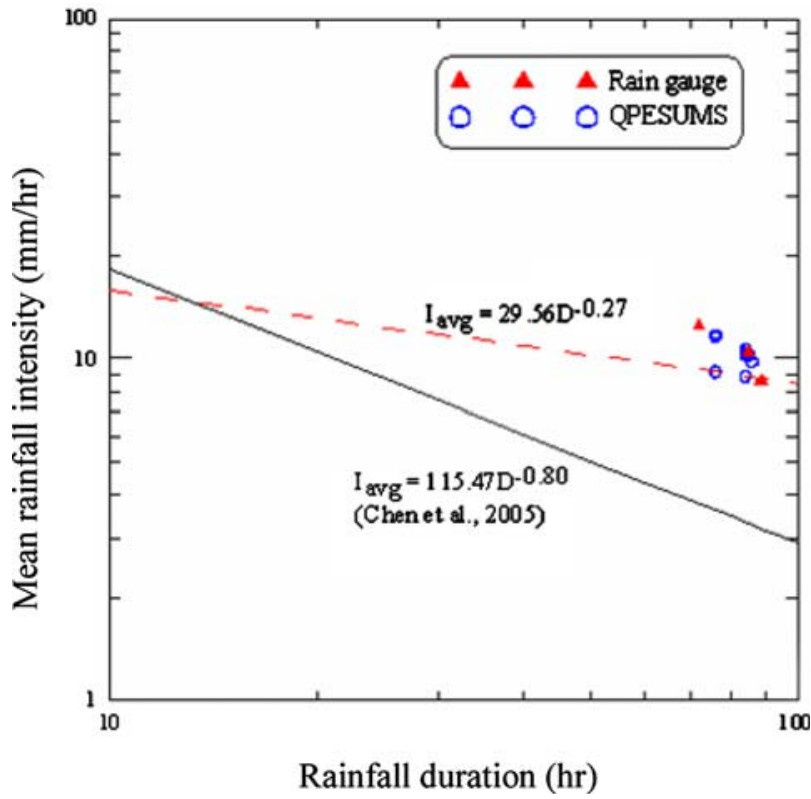




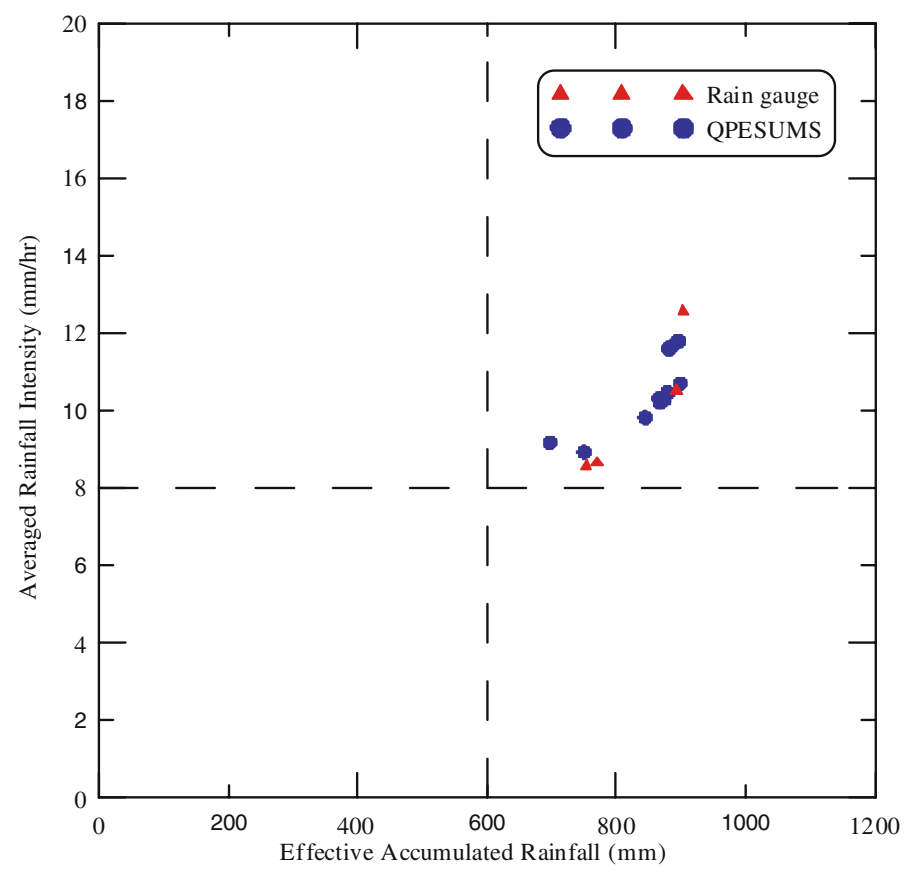

Fig. 13 Averaged rainfall intensity versus effective accumulative rainfall to trigger debris flow in the study area

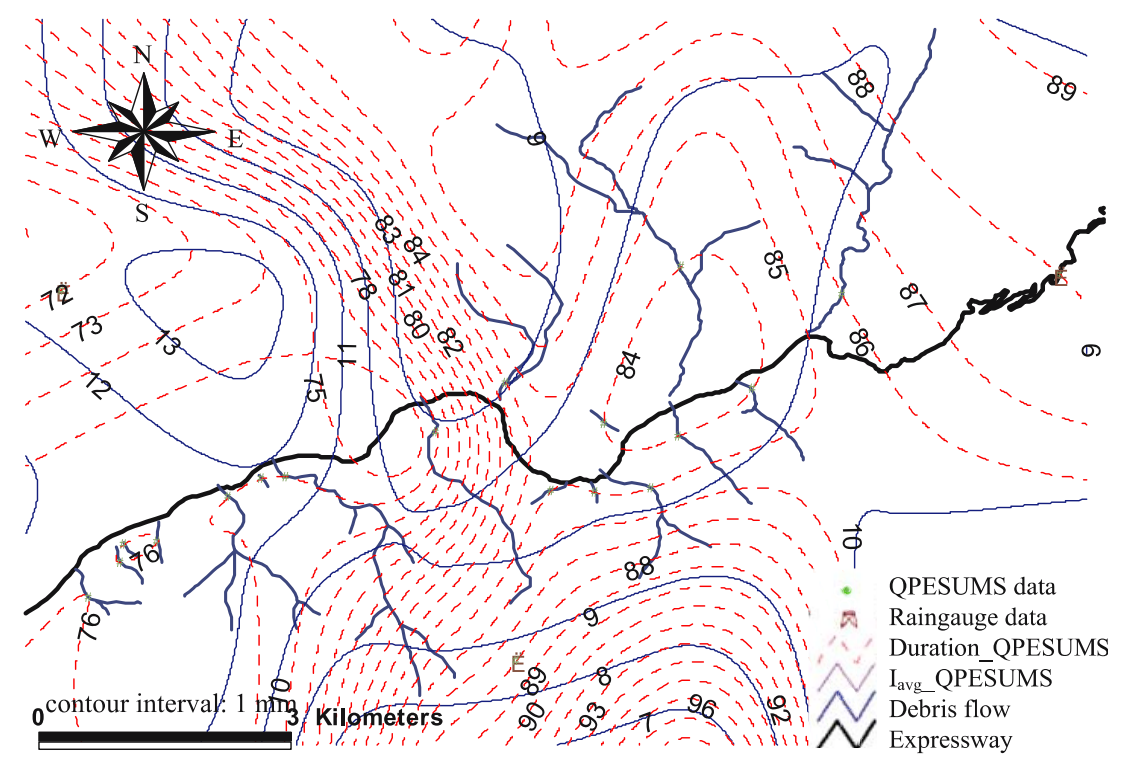

Fig. 14 Isopleth map of averaged rainfall intensity and duration to trigger debris flow in the study area 
induced debris flow is better monitored by averaged rainfall intensity than by the critical rainfall intensity (Chen et al. 2005). The latter is the minimum rainfall intensity at the time of debris flow initiation.

The averaged rainfall intensity and rainfall duration $(D)$ to trigger debris flow recorded by the four rain-gauge stations and by QPESUMS at the 17 overflow points are shown in Fig. 12. The regression formula for averaged rainfall intensity $(I)$ to initiate debris flow against $\mathrm{D}$ can be represented by Eq. 1 . The values of $I_{\text {avg }}$ in this equation are above the lower bound of debris flow threshold line as documented in Chen et al. (2005) for 61 debris flow cases in Taiwan.

$$
I_{\mathrm{avg}}=29.56 \mathrm{D}^{-0.27}
$$

A minimum averaged rainfall intensity of $8 \mathrm{~mm} / \mathrm{h}$ and an effective cumulated rainfall of $650 \mathrm{~mm}$ were necessary to trigger debris flow in the study area as presented in Fig. 13. A critical isopleth map for rainfall triggering of debris flow in the pilot area is proposed in Fig. 14, which is the distribution of threshold value prepared for real-time debris flow monitoring in the study area.

\section{Conclusion}

A regional threshold of averaged rainfall intensity and duration for triggering of debris flow was investigated in the pilot area. The minimum cumulative rainfall was $650 \mathrm{~mm}$ and a rainfall intensity of $8 \mathrm{~mm} / \mathrm{h}$ prolonged to $15 \mathrm{~h}$ to initiate debris flow in the study area. The intense and prolonged rainfall contributed to the initiation of debris flow in the study area. In this area with numerous earthquake-induced landslides within the catchments, averaged rainfall intensity and duration is a set of proper parameters for setting up a debris flow triggering threshold line.

Experiences from the debris flow disasters show that the effective watershed area within the catchment is an important index for the triggering of debris flow under intense and prolonged rainfall. By the results of rainfall distribution monitoring by QPESUMS, it is necessary to divide a wide area into smaller zones according to the variety of geologic conditions and the effects of topography on distributions of rainfall. In the future, it seems feasible to track the water flow time series in realtime at the historical debris flow's overflow point for examining the peak discharge within the catchment to trigger debris flow.

Acknowledgements The material in Table 1 is obtained from the Soil \& Water Conservation Bureau and from an unpublished document: Liao J. J., Dong J. J., Lin M. L., and Jeng F. S.: 2004, Suggestions of rehabilitated strategy for Puwu expressway and Nanfeng village (in Chinese).

\section{References}

Caine N (1980) The rainfall intensity-duration control of shallow landslides and debris flow. Geografiska Annaler 62:23-27

Cannon SH, Ellen SD (1985) Rainfall conditions for abundant debris avalanches in San Francisco Bay California. California Geol 38:267-272

Springer 
Chen CY, Chen TC, Yu FC, Yu WH (2005) Rainfall duration and debris-flow initiated studies for real-time monitoring. Environ Geol 47:715-724

Crosta G, Frattini P (2002) Rainfall thresholds for triggering soil slips and debris flow, Proceedings of 2nd Plinius International Conference on Mediterranean Storms, Siena, Italy

Johnson D, Smith M, Koren V, Finnerty B (1999) Comparing mean areal precipitation estimates from NEXRAD and rain gauge networks. J. Hydrologic Eng. 4:117-124

Keefer DK, Wilson RC, Mark RK, Brab EE, Brown WM, Ellen SD, Harp EL, Wieczorek GF, Alger CS, Zatkin RS (1987) Real-time landslide warning during heavy rainfall. Science 238:921-925

Lee CS, Huang LR, Shen HS, Wang ST (2006) A climatology model for forecasting typhoon rainfall in Taiwan. Natural Hazards 37:87-105

Takahashi T (1981) Debris flow. Ann Rev Fluid Mech 13:57-77

Vieux BE, Vieux JE, Chen CR, Howard KW (2003) Operational deployment of a physics-based distributed rainfall-runoff model for flood forecasting in Taiwan. IAHS General Assembly at Sapporo, Japan, July 3-11

Wieczorek GF (1987) Effect of rainfall intensity and duration of on debris flows in Central Santa Cruz Mountains. California, flows/ avalanches: process, recognition, and mitigation, Geological Society of America. Rev Eng Geol 7:93-104

Wilson RC, Jayko AS (1997) Preliminary maps showing rainfall thresholds for debris-flow activity, San Francisco Bay region, California. OPEN-FILE REPORT 97-745 F, US Geological Survey

Xie H, Zhou X, Vivoni ER, Hendrickx JMH, Small EE (2005) GIS-based NEXRAD stage III precipitation database: automated approaches for data processing and visualization. Comput Geosci 31: 65-76

Yates DN, Warner TT, Leavesley GH (2000) Prediction of a flash flood in complex terrain. Part II: A comparison of flood discharge simulations using rainfall input from radar, a dynamic model, and an automated algorithmic system. J Appl Meteorol 39:815-825

Young CB, Bradley AA, Krajewski WF, Kruger A, Morrissey ML (2000) Evaluating NEXRAD multisensor precipitation estimates for operational hydrologic forecasting. J Hydrometeorol $1: 241-254$ 